\title{
A threshold for asbestos related lung cancer
}

\author{
K BROWNE
}

From the Department of Occupational Medicine, Brompton Hospital, London SW3

Whether a threshold exists for asbestos related lung cancer is a question of great importance. If a threshold can be shown for workers occupationally exposed to asbestos then most of the anxieties about environmental exposure, which is usually at least three orders of magnitude less than the current permitted occupational exposure, ${ }^{12}$ are misplaced. On the other hand, if a threshold does not exist then the practice of awarding compensation for lung cancer only when there is pre-existing asbestosis should be reviewed.

From the report of the United Kingdom Advisory Committee on Asbestos in $1979^{3}$ onwards, a succession of governmental or semiofficial reports have appeared in Europe and America. ${ }^{124-7}$ All have subscribed, with varying misgivings, to the "no threshold" hypothesis. In doing so they appear to have been unduly influenced by statisticians impressed by the linearity of the dose-response curve at the high exposures of the past, ranging from the probable equivalents of 150 to $6000 \mathrm{f} / \mathrm{ml}$ years in one major series. But no report provides a detailed examination of mortality at the much lower levels relevant to contemporary exposures.

Nevertheless, Weill at the 1979 conference at Lyon suggested that there were indications that the carcinogenic dose of asbestos might be higher than the fibrogenic dose. ${ }^{8}$ Since then much more evidence has become available.

\section{Published studies}

In 1984 McDonald listed seven industrial groups where exposure to asbestos for each subject was estimated individually in duration and intensity. ${ }^{9}$ To these may be added an eighth recently published. ${ }^{10}$ Data from each of these, and from a major study for which only duration of exposure was available, ${ }^{11}$ are set out below.

Present address: Cape Industries plc, Exchange Road, Watford, Herts WD1 7EG.

Accepted 27 January 1986
CHRYSOTILE MINING AND MILLING IN QUEBEC 1213

Exposure up to 7 years before death (mpcf years)

$\begin{array}{lllllll}<6 & 6-9 & -29 & -99 & -299 & -599 & -999\end{array}$

Relative risk of lung cancer

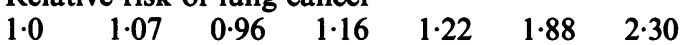

As may be seen, no increase in the relative risk of lung cancer occurred below $30 \mathrm{mpcf}$ years (estimated by the authors to approximate to $100 \mathrm{f} / \mathrm{ml}$ years). The comment is made in another paper that for the 1904 men in the cohort with at least 20 years employment in the lower dust concentrations (averaging $6.6 \mathrm{mpcf}$ or about $20 \mathrm{f} / \mathrm{ml}$ ) excess mortality for pneumoconiosis was statistically significant but not for lung cancer. ${ }^{14}$
CEMENT, TEXTILE, AND FRICTION PRODUCTS IN NEW JERSEY ${ }^{15}$
Total dust exposure (mpcf years)
$\begin{array}{llllll}<25 & 25-62 & -125 & -249 & -400 & -749\end{array} 2750$
SMR for respiratory cancer
$\begin{array}{lllllll}154 & 258 & 109 & 250 & 327 & 500 & 557\end{array}$

The authors comment that the SMR of the first three groups taken together $(166 \cdot 7)$ while raised when the entire United States is used as the standard is probably no higher than that of comparable employees not exposed to asbestos.

CEMENT PRODUCTS IN LOUISIANA 16

Cumulative exposure in first 20 years (mpcf years)

$\leqslant 10 \quad 11-50 \quad-100 \quad-200 \quad \geqslant 200$

Lung cancer SMR

$\begin{array}{lllll}77 & 70 & 26 & 290 & 226\end{array}$

Case-control relative risk

$\begin{array}{lllll}1.0 & 1.14 & 0.52 & 2.85 & 2.75\end{array}$

In this cohort both the SMR and a study matching each case with four controls were said to show "an excess of respiratory malignancy only at exposure levels above 100 mpcf years." 
TEXTILES IN SOUTH CAROLINA AND

PENNSYLVANIA 1718

Dust exposure accumulated to 10 years before death (mpcf years)

$\begin{array}{lll}<10 & 10-19 & -39\end{array}$

S Carolina

$1 \quad 0.98$

Pennsylvania

$\begin{array}{lllll}1 & 0.83 & 1.54 & 2.90 & 6.82\end{array}$

SMR:

S Carolina

$143 \quad 183$

Pennsylvania

$\begin{array}{lllll}67 & 84 & 156 & 160 & 416\end{array}$

The numbers of deaths in the second exposure category (10-19 mpcf years) were small and the increase in the SMR compared with the lowest exposure category was not significant. It must be noted, however, that, by contrast with the case-control figures for relative risk in the same series, there was no evidence for a threshold.

\section{FRICTION PRODUCTS IN THE UNITED KINGDOM ${ }^{19}$ \\ Cumulative exposure (f/ml years) \\ $\begin{array}{llll}0-9 & 10-49 & -99 & -356\end{array}$ \\ Lung cancer relative risk

$\begin{array}{llll}1.0 & 0.79 & 0.86 & 0.88\end{array}$

The relative risk showed no increase with increasing duration of employment. The overall SMR for lung cancer was 106 , an increase that was not statistically significant. Nevertheless, nine deaths from mesothelioma were attributable to work at the factory, together with a small number of cases of clinical asbestosis (though no deaths).

FRICTION PRODUCTS IN CONNECTICUT ${ }^{20}$ Cumulative exposure (f/ml years)

$\begin{array}{lcccc}<10 & 10-19 & -39 & -79 & \geqslant 80 \\ \text { Lung cancer (from case-control study) } & \\ \begin{array}{l}1 \\ 0.40\end{array} & 0.91 & 1.40 & 1.13 \\ \text { Relative risk (from SMR) } & & \\ 1 & 0.59 & 0.64 & 0.98 & 0.31\end{array}$

The dose-response pattern in this study is confusing and is discussed at length by the authors, who suggest that there is possible evidence of some increase in risk with increasing exposure. Nevertheless, the men in the lowest cumulative exposure category had the highest mortality regardless of duration of employment, as the following table shows:
Lung cancer SMRs Exposure (mpcf years)

$\begin{array}{lccc}\begin{array}{l}\text { Duration of } \\ \text { service (years) }\end{array} & <10 & 10-39 & 40- \\ <1 & 180 & - & - \\ 1-4 & 166 & 83 & - \\ 5- & 150 & 110 & 125\end{array}$

TEXTILES IN UNITED KINGDOM ${ }^{10}$

Cumulative exposure $(\mathrm{p} / \mathrm{ml}$ years)

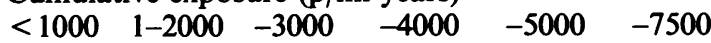

SMR calculated from authors' data

$\begin{array}{llllll}1.15 & 1.04 & 1.67 & 1.06 & 2.33 & 2.22\end{array}$

An abrupt rise in SMR for exposures over $4000 \mathrm{p} / \mathrm{ml}$ years (about $100 \mathrm{f} / \mathrm{ml}$ years) is also seen among men first exposed after 1951 .

INSULATION MATERIALS NEW JERSEY 11

Length of time worked (months)

$\begin{array}{lllllll}<1 & -2 & -3 & -5 & -11 & -23 & \geqslant 24 \\ \begin{array}{lcccc}\text { SMR } \\ 2.94\end{array} & 2.84 & 2.78 & 2.45 & 3.52 & 5.59 & 6.50 \\ \begin{array}{l}\text { Relative risk } \\ 1\end{array} & 0.97 & 0.95 & 0.83 & 1.20 & 1.90 & 2.21\end{array}$

No attempt to estimate cumulative exposures was made in this study, which has been subjected to much criticism. ${ }^{25}$ Durations of exposures were given, however, and the figures have been included since they are frequently quoted as evidence of the high risk of lung cancer associated with brief exposures to asbestos. If the absolute risk levels should be disregarded as inappropriate, as Liddell suggests, ${ }^{5}$ it may be seen that the relative risk began to rise only after exposures of more than six months in this extremely dusty factory.

\section{STUDIES SHOWING NO INCREASED RISK}

Several studies have recently appeared of occupational exposures to asbestos in which rates of lung cancer have not been raised. These include asbestos cement factories ${ }^{2122}$ and dockyard ${ }^{2324}$ and shipyard workers. ${ }^{25}$ The most fully documented of these is the Devonport naval dockyard study ${ }^{23}$ and in this, as in some of the other studies, confirmation that asbestos exposure was not negligible is provided by the occurrence of mesotheliomas, pleural changes, and even some asbestosis.

\section{Discussion}

The data given above show that every industrial group of asbestos workers with adequate data on individual duration and intensity of exposure provides some evidence of a threshold of cumulative exposure below which the risk of lung cancer does not appear to be raised. The evidence for a threshold is 
also supported by one well documented study giving duration of exposure only, and by several studies showing no increase in lung cancer risks despite the presence of low levels of other asbestos related disease. The interpretation of low level dose response data is complicated by the inclusion of a disproportionate number of short term workers, who frequently incur a higher incidence of lung cancer. 2202627 This difficulty, however, does not apply to series showing no increase in lung cancer rates or to case-control studies matched for duration of employment.

It is noteworthy that where estimates of exposure are given, the threshold for increased risk of lung cancer appears to be somewhere in the range of 25-100 f/cc years. The Ontario Royal Commission suggested that a threshold for clinical asbestosis was in the range of $25 \mathrm{f} / \mathrm{cc}$ years. A threshold for asbestos related lung cancer at or above the threshold for asbestosis does not prove that the risks are linked. Nevertheless, it is consistent with the hypothesis that the increased risk of lung cancer due to exposure to asbestos occurs only where asbestosis is already present, a belief for which the evidence is now considerable. ${ }^{27} 28$

\section{References}

' Royal Commission on matters of health and safety arising from the use of asbestos in Ontario. Report. Toronto: Ontario Ministry of the Attorney General, 1984.

${ }^{2}$ Doll R, Peto J. Effects on health of exposure to asbestos. London: HMSO, 1985.

${ }^{3}$ Acheson ED, Gardner MJ. The ill effects of asbestos on health. Asbestos: final report of the advisory committee 2. London: HMSO, 1979.

${ }^{4}$ National Research Council. Asbestiform fibres; non-occupational health risks. Washington: NRC, 1984.

${ }^{5}$ Acheson ED, Gardner MJ. Asbestos: the control limit for asbestos. London: HMSO, 1983.

${ }^{6}$ Nicholson WJ. Criteria document for Swedish occupational standards: asbestos and inorganic fibres. Arbete och Halsa 1981;17:1-103.

${ }^{7}$ Schneiderman ML, Nisbet ICT, Brett SM. Assessment of risks posed by exposure to low levels of asbestos in the general environment. Bundesgesundheitsamtes-Berichte 1981;4:1-28.

${ }^{8}$ Weill H. Asbestos-a summing up. In: Wagner JC, ed. Biological effects of mineral fibres. Lyon: International Agency for Research on Cancer, 1980:868. (IARC sci pub No 30.)

${ }^{9}$ McDonald JC. Mineral fibres and cancer. Ann Acad Med Singapore 1984;13:345-52.
${ }^{10}$ Peto J, Doll R, Herman C, Binns R, Goffe T, Clayton R. Relationship of mortality to measures of environmental pollu- ? tion in an asbestos textile factory. Ann Occup $\mathrm{Hyg} \underset{\text { 1985;29:305-55. }}{\stackrel{\vec{S}}{\vec{S}}}$

${ }^{11}$ Seidman H, Selikoff IJ, Hammond EC. Short-term asbestos work $\bar{O}$ exposure and long-term observation. Ann NY Acad Sci 드 1979;330:61-89.

${ }^{12}$ Liddell FDK, McDonald JC, Thomas DC. Methods of cohort $\frac{\omega}{\vec{D}}$

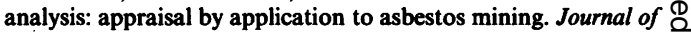
the Royal Statistical Society 1977;140:469-91.

${ }^{13}$ McDonald JC, Liddell FDK, Gibbs GW, Eyssen GE, McDonald है AD. Dust exposure and mortality in chrysotile mining, 1910-75. $\vec{\circ}$ Br J Ind Med 1980;37:11-24.

${ }^{14}$ Liddell FDK, McDonald JC. Radiological findings as predictors $\overrightarrow{\vec{\omega}}$ of mortality in Quebec asbestos workers. Br J Ind Med 1980;37:257-67.

${ }^{15}$ Enterline P, De Coufle P, Henderson V. Respiratory cancer in $\mathbb{D}$ relation to occupational exposures among retired asbestos workers. Br J Ind Med 1973;30:162-6.

${ }^{16}$ Hughes J, Weill $\mathrm{H}$. Lung cancer risk associated with manufacture $\infty$ of asbestos-cement products. In: Wagner JC, ed. Biological iv effects of mineral fibres. Lyon: International Agency for $G$ Research on Cancer, 1980:627-35.

${ }^{17}$ McDonald AD, Fry JS, Woolley AJ, McDonald JC. Dust 을 exposure and mortality in an American chrysotile textile plant. Br J Ind Med 1983;40:361-7.

${ }^{18}$ McDonald AD, Fry JS, Woolley AJ, McDonald JC. Dust exposure and mortality in an American factory using chrysolite, amosite, and crocidolite in mainly textile manufacture. $\mathrm{Br} J$ Ind $\stackrel{\oplus}{\longrightarrow}$ Med 1983;40:368-74.

${ }^{19}$ Berry G, Newhouse ML. Mortality of workers manufacturing friction materials using asbestos. Br J Ind Med 1983;40:1-7.

${ }^{20}$ McDonald AD, Fry JS, Woolley AJ, McDonald JC. Dust exposure and mortality in an American chrysotile asbestos friction products plant. Br J Ind Med 1984;41:151-7.

${ }^{21}$ Thomas HF, Benjamin IT, Elwood PC, Sweetnam PM. Further follow up study of workers from an asbestos cement factory. $\mathrm{Br}$ $J$ Ind Med 1982;39:273-6.

${ }^{22}$ Hodgson JT, Jones RD. Mortality of asbestos workers in England and Wales 1971-81. Br J Ind Med 1986;43:158-65.

${ }^{23}$ Rossiter CE, Coles RM. HM Dockyard, Devonport: 1974 mortality study. In: Wagner JC, ed. Biological effects of mineral fibres. Lyon: International Agency for Research on Cancer, 1980:713-21. (IARC sci pub No 30.)

${ }^{24}$ Farebrother MJB, Heller RF, O'Brien I, Azzoparde A, Telfa TP, Young $M$. Occupation and lung cancer in a naval dockyard area. (Abstract.) Thorax 1983;38:225.

${ }^{25}$ Newhouse ML, Oakes D, Woolley AJ. Mortality of welders and other craftsmen at a shipyard in NE England. Br $J$ Ind Med 1985;42:406-10.

${ }^{26}$ Fox AJ, Collier PF. Low mortality rates in industrial cohort studies due to selection for work and survival in the industry. $\mathrm{Br} J$ Prev Soc Med 1976;30:225-30.

${ }^{27}$ Browne $\mathrm{K}$. Is asbestos or asbestosis the cause of the increased risk of lung cancer in asbestos workers? $\mathrm{Br} J$ Ind Med 1986;43:145-9.

${ }^{28}$ Sluis-Cremer GK. The relationship between asbestosis and bronchial cancer. Chest 1980;70:380-1. 